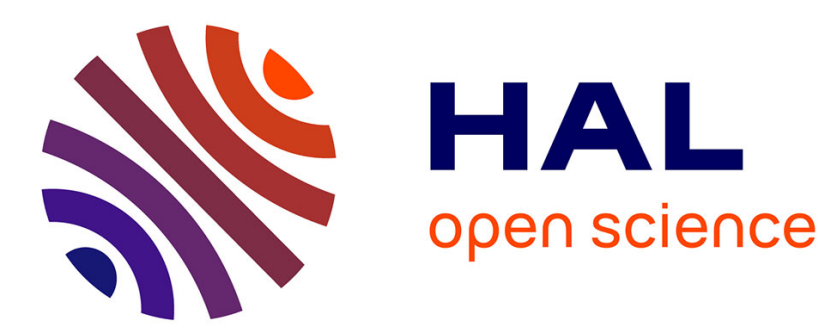

\title{
Integrated sheetmetal production planning for laser cutting and bending
}

Bart Verlinden, Dirk Cattrysse, Dirk van Oudheusden

\section{To cite this version:}

Bart Verlinden, Dirk Cattrysse, Dirk van Oudheusden. Integrated sheetmetal production planning for laser cutting and bending. International Journal of Production Research, 2007, 45 (02), pp.369-383. 10.1080/00207540600658062 . hal-00512900

\section{HAL Id: hal-00512900 https://hal.science/hal-00512900}

Submitted on 1 Sep 2010

HAL is a multi-disciplinary open access archive for the deposit and dissemination of scientific research documents, whether they are published or not. The documents may come from teaching and research institutions in France or abroad, or from public or private research centers.
L'archive ouverte pluridisciplinaire HAL, est destinée au dépôt et à la diffusion de documents scientifiques de niveau recherche, publiés ou non, émanant des établissements d'enseignement et de recherche français ou étrangers, des laboratoires publics ou privés. 


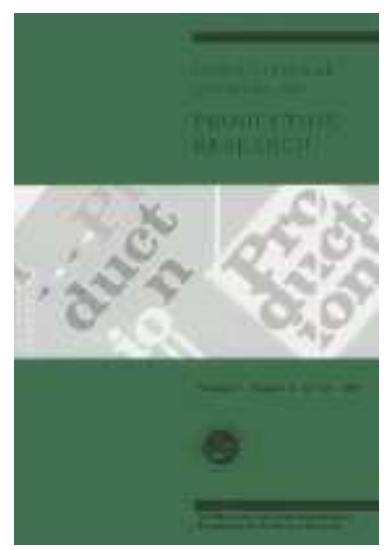

\section{Integrated sheetmetal production planning for laser cutting and bending}

\begin{tabular}{|r|l|}
\hline Journal: & International Journal of Production Research \\
\hline Manuscript ID: & TPRS-2005-IJPR-0578.R1 \\
\hline Manuscript Type: & Original Manuscript \\
\hline Date Submitted by the & 13 -Feb-2006 \\
\hline Complete List of Authors: & $\begin{array}{l}\text { Verlinden, Bart; Katholieke Universiteit Leuven, Centre for } \\
\text { Industrial Management } \\
\text { Cattrysse, Dirk; Katholieke Universiteit leuven, Centre for Industrial } \\
\text { Management } \\
\text { Van Oudheusden, Dirk; Katholieke Universiteit Leuven, Centre for } \\
\text { Industrial Management }\end{array}$ \\
\hline Keywords (user): & \begin{tabular}{l} 
PRODUCTION PLANNING, OPERATIONAL RESEARCH \\
\hline Keywords:
\end{tabular} \\
\hline
\end{tabular}

\section{S ScholaroNE \\ Manuscript Central}


Bart Verlinden

Centre for Industrial Management

Celestijnenlaan 300A

3001 Heverlee

$\mathrm{T}:+32(0) 16.32 .25 .69$

$F:+32(0) 16.32 .29 .86$

Bart.verlinden@cib.kuleuven.be

Dirk Cattrysse

Centre for Industrial Management

Celestijnenlaan 300A

3001 Heverlee

$\mathrm{T}:+32(0) 16.32 .25 .64$

$\mathrm{F}:+32(0) 16.32 .29 .86$

Dirk.cattrysse@cib.kuleuven.be

Dirk Van Oudheusden

Centre for Industrial Management

Celestijnenlaan 300A

3001 Heverlee

$\mathrm{T}:+32(0) 16.32 .25 .65$

$F:+32(0) 16.32 .29 .86$

Dirk.vanoudheusden@ cib.kuleuven.be 


\title{
Integrated sheetmetal production planning for laser cutting and bending
}

\begin{abstract}
Mathematical models, sometimes implemented in commercial software, allow optimisation of individual machines based on specific criteria. For sheetmetal operations, cutting, punching and air bending are subject of extensive research and both process planning and production planning can nowadays be automated to some extent.

$2 \mathrm{D}$ cutting operations focus on minimisation of waste material and $3 \mathrm{D}$ bending operations on minimisation of time consuming setups. However, when integrating both processes the benefits from separate machine optimisation may disappear. Optimised nesting of parts at the laser can create additional setups at the pressbrake. In this paper, the use of OR techniques for integrated production planning for sheetmetal operations is analysed. An integrated production planning model is proposed, aiming at creating feasible groupings of parts while at the same time minimising the number of time consuming setups at the pressbrake.. Simulation is used to verify the applicability of the integrated approach.
\end{abstract}

A case study is carried out to verify the model's ability to generate feasible production plans. Those production plans are compared to a reference case, representing the current way of planning An average makespan reduction of $4.11 \%$ is obtained, resulting in an average yearly savings of about 10 days. 


\section{Introduction}

During the past few decades, increased competition urged manufacturing companies to search for methods to assist them. The rapid advance of computer systems has triggered the introduction of automation in manufacturing environments. Computer aided design (CAD) and computer aided manufacturing (CAM) systems are widely present and considered indispensable for the survival of companies.

At the earliest design stage, CAD systems are used to computerise the whole process of drawing and redrawing the desired part. Most modern CAD systems allow a part to be built up from several re-usable 3D components, thus automating the time-consuming design process to a large extent.

The use of computers has also entered the manufacturing stage through computer aided manufacturing (CAM). The CAD file is converted into a sequence of processes for manufacture on a numerically controlled (NC) machine. The integration of both $C A D$ and $C A M$, resulted in CAE (computer aided engineering). In the sheetmetal world, CAD-CAM systems are widely used. Typically, sheetmetal parts are produced by a number of different 2D and 3D operations. In this study, we only consider the cutting and bending process. Starting from a flat blank, a suitable cutting process will be chosen to produce the $2 \mathrm{D}$ part. Since material is an important cost component, optimisation of this process will be driven by the need to decrease the scrap percentage.

Nesting algorithms, implemented in computer systems, will be used to group a number of parts with the same thickness on a single sheet. If the required end product is a 3D part, air bending will be applied. The bending process is labour intensive and requires an operator continuously. The production time of a 3D part is influenced by the number of time-consuming setups between parts. A part 
requires a certain production layout, i.e. a sequence of punch-die combinations positioned on the pressbrake. Interchanging production layouts is time consuming and thus needs to be avoided as much as possible. In order to achieve this, dedicated planning algorithms have been developed, but so far they have not been implemented in specialised software. In most companies, planning of the air bending process is still highly experience-based.

Although optimisation of the distinct processes is possible to some extent, sequential implementation leads to sub-optimisation. The benefits obtained from optimising the separate processes will counteract one another since different measures of performance are used. This paper focuses on an integrated approach for production planning of sheetmetal parts for laser cutting and air bending and has five sections. Next section elaborates on the optimisation of the distinct processes. Both the laser cutting and bending process are discussed. Relevant research is mentioned and a literature overview is given. Section 3 reflects upon the need for an integrated approach. The model is discussed and the data-requirements are mentioned. The procedure is explained and the different situations for testing are discussed. The characteristics of the simulation tool, to verify the applicability of an integrated approach, are mentioned. Section 4 discusses the case study conducted to verify the model's feasibility and applicability for sheetmetal parts. Finally, section 5 discusses the results and concludes the paper. 


\section{Sheetmetal operations: optimisation of the distinct processes}

\subsection{Sheetmetal operations}

Although unknown to many, sheetmetalworking is a production process that has been in existence since 8000 B.C. (Fries-Knoblach, 1999). Although it is sometimes viewed as archaic and uninteresting, during the last two decades this perception has changed due to the introduction of CNC machines and new processes such as laser cutting. Nowadays sheetmetalworking is viewed by designers as a viable option, not only for structural components, but also for designing durable consumer goods (W. Serruys 2002).

Sheetmetal operations are used to transform a flat blank into 2D or 3D objects by applying different processes: punching, cutting, bending, welding, painting, etc. The thickness typically varies between 1 and $10 \mathrm{~mm}$, although other thicknesses are possible. In the first step, a sheared sheet will be punched or cut with the laser, resulting in a 2D intermediate or end product. The complete cutting process can be automated, allowing the laser machine to operate autonomously.

If $3 \mathrm{D}$ parts are required, air bending is used. By applying a vertical force, the sheet is forced into a die. Depending on the magnitude of this force, the bend angle will vary. Each bend line requires a certain toolset.

Such toolset comprises a punch and a die, positioned on the pressbrake. For bending one part, often consisting of multiple bend lines, different toolsets might be needed.

Those sets will all be positioned on the pressbrake, resulting in a production layout. Changing production layouts is time consuming and should be avoided as much as possible. The operator's experience plays an important role in reducing the number of tool changes at the pressbrake. 
Figure 1 displays the different sheetmetal operations. The after-treatment operations such as welding and painting are not considered.

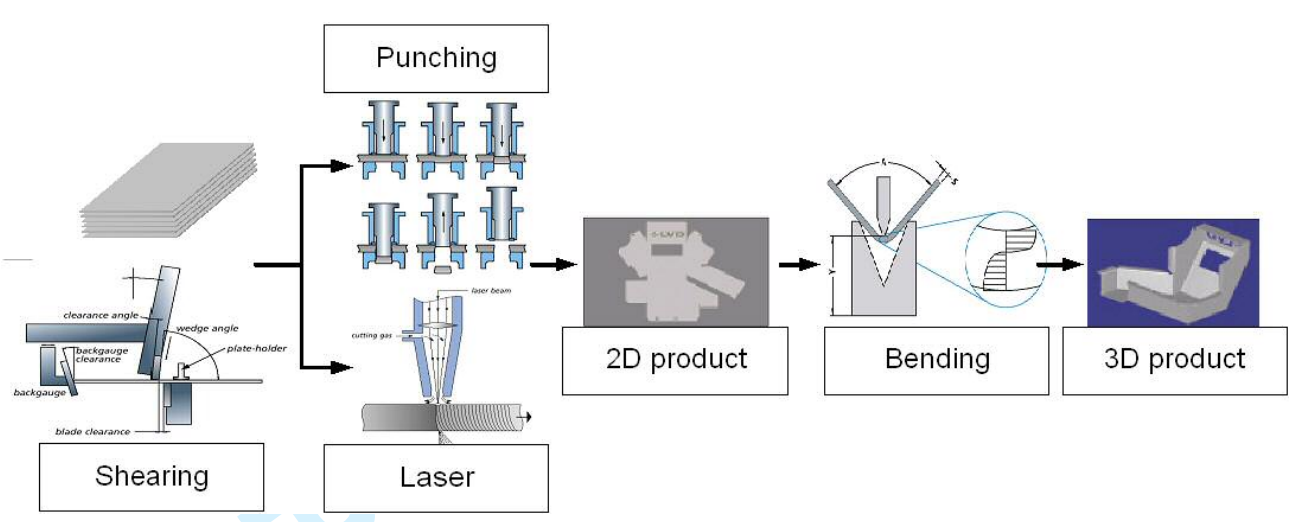

Figure 1: Sheetmetal operations 


\subsection{Laser cutting: nesting of the orders}

Currently, many manufacturing companies use smaller lot sizes than before. To decrease the costs for sheetmetal punching and laser cutting, nesting is applied. Nesting implies combining multiple orders of the same material on a sheet, such that the amount of waste material is reduced.

The problem of combining different parts on a sheet or coil is known as the cutting stock problem. Gilmore and Gomory (1965) formulated the problem as an integer programming problem. First, cuts will be made parallel to one edge, followed by cuts perpendicular to the first. Many researchers have used linear programming techniques to solve the cutting stock problem (Murty 1983, Farley 1988, Schultz 1995). Adamowicz (1975) proposed a two stage approach. In the first stage the parts are encaged in minimum area rectangular modules either singly or in combination with other parts. In the second stage, those modules are grouped on a sheet, minimising the waste material. An important remark is the fact that these simplifications can create additional waste material. Parallelogram shaped parts can ideally be nested without any waste material. However, when representing them by rectangular shapes, waste material is introduced. 
Agrawal (1993) used a branch and bound technique to nest rectangular shapes of the same size on sheets, while minimising the trim loss. Throughout past decades extensive research has been conducted on the 2D rectangular cutting stock problem and a survey is given by Cheng (1994). A sequential heuristic procedure is discussed by Suliman (2006).

As computer systems became more powerful, immediate nesting of the complex parts, instead of approximating rectangles, was considered. The so-called irregular pattern problem received much attention in the nineties (Dagli 1990, Poshyonada 1992, Oliveira 1993). Since the problem of nesting irregular shapes requires large computational times, mostly heuristic methods were developed to solve the problem. Grinde and Cavalier (1995) proposed a method for combining two irregular shapes into a convex enclosure for which the area is minimised. Those convex enclosure areas can then be combined to fill up a sheet. Different rotation angles of the parts have been investigated (Chow 1977, Nee 1984, Prasad 1995), resulting in good but time consuming methods. Nye (1999) developed an exact algorithm to nest irregular convex blanks in strips. By applying different orientation angles between the different parts, the waste material can be reduced. Nowadays, those nesting algorithms have been implemented in software tools to assist the operators of cutting machines.

\subsection{Bending: minimisation of the number of setups}

For the bending operation, production time minimisation is required. Research has been conducted on optimisation of the bending process, mainly focusing on tool selection and bend sequencing (Lin 1995, S.K. Ong 1997, Duflou 2005, Nguyen 2005). Previously mentioned research mainly focuses on process planning issues. As far as production planning issues are concerned, very limited publications can be found. Collin et al. (2003) focused on minimising the number 
of setups at the pressbrake. A travelling purchaser formulation (TPP) of the problem allows to minimise the number of tool changes and the total processing time. Solving the TPP is carried out by solving a simple plant location problem (SPLP) combined with a travelling salesman problem (TSP). The number of setups needed, and consequently the total required set-up time, is reduced to a large extent. The sum of all process times is lowered compared to the reference situation.

Although some (preliminary) optimisation models are available for the bending process, production planning mainly relies on the experience of the operator since those few planning algorithms have not yet been implemented. An ERP system generates the requirements for sheetmetal parts within a certain time horizon. The pressbrake operator can schedule the parts, based on his knowledge. Minimisation of production layout changes will be taken into account, but is not the sole driving factor. Other more practical considerations such as personal preference, type of bend line, amount of parts and timing aspects will influence the planning. Based on the operator, different plans will be generated for the same batch of orders. Capturing the knowledge of machine operators is rather difficult, explaining the limited amount of dedicated literature on this topic.

When discussing integrated planning, most attention is focused on integration of high level planning (MRP) with shop floor scheduling

(Buckley 1988, Riane 2001). Integrating different sequential sheetmetal processes with distinct optimisation criteria for production planning was, to the best of the authors' knowledge, never attempted.

To overcome the problems due to sub-optimisation of the distinct processes, an integrated approach is proposed. The main target of such integrated approach is to group the parts in an intelligent way, while at the same time taking into account minimisation of the number of time consuming setups at the pressbrake. This 
means that if a certain production layout can be used for a series of parts, this should be encouraged. The generated production plans thus indicate the parts to group on a sheet, the production layouts to use at the pressbrake and the sequence for bending the parts. Note that the proposed approach does not generate the final nesting layout of the different sheets. The output of the model is a grouping of parts per sheet, taking into account the sheet's capacity and the required safety zones. Determining the best layout of those parts on a sheet should be done with specialised software (rotations of parts, translations, etc.).

Note also that the sequence for bending the parts is not the bend sequence for an individual part as determined by the process plan. The bend sequence of an individual part indicates the order for executing the different bend strokes of that part, taking into account possible collisions between the tools, the part and the machine (e.g. bendline1 - bendline4 - bendline2). Typically, such bend sequence for an individual part is translated into NC-code and sent to the pressbrake. The sequence generated by the proposed planning model, indicates the consecutive order of the different parts (e.g. part1 - part4 - part12 - part11) and not the individual bend sequence. 


\section{A model for integrated planning}

\subsection{Mathematical formulation}

For the model as depicted in figure 2, a number of parameters will be used:

- i: job index

- j: production layout index

- $\mathrm{t}$ : plate index

- $f_{j t}$ : changeover time when using layout $j$ for sheet $t$

- $\quad z_{i t}=0-1$ parameter indicating if job $i$ can be nested on sheet $t$, based on the thickness and material

- $\quad p_{i j}$ : the production time for producing job $i$ with layout $j$ (i.e. cutting and bending time). Note that the cutting time of a part is independent of the production layout chosen for the bending process.

- $\quad c_{\mathrm{ij}}$ : 0-1 parameter indicating if job $\mathrm{i}$ can indeed be made with layout $\mathrm{j}$

- $\quad c a_{t}$ : capacity of plate $t$

The variables to be determined by the model are:

- $y_{j t}: 0-1$ variable indicating if layout $j$ is used for sheet $t$

- $\quad \mathrm{X}_{\mathrm{ijt}}: 0-1$ variable indicating whether job $\mathrm{i}$ will be nested on sheet $\mathrm{t}$, and assigned toolset $\mathrm{j}$ 


$$
\begin{aligned}
& \operatorname{minimise} \sum_{\mathrm{j}} \sum_{\mathrm{t}} \mathrm{f}_{\mathrm{jt}} \mathrm{y}_{\mathrm{jt}}+\sum_{\mathrm{i}} \sum_{\mathrm{j}} \sum_{\mathrm{t}} \mathrm{x}_{\mathrm{ijt}} \mathrm{p}_{\mathrm{ij}} \\
& \text { s.t. } \\
& \mathrm{x}_{\mathrm{ijt}} \leq \mathrm{y}_{\mathrm{jt}} \quad(\text { for } \forall \mathrm{i}, \mathrm{j}, \mathrm{t}) \\
& \left.\sum_{\mathrm{j}} \sum_{\mathrm{t}} \mathrm{x}_{\mathrm{ijt}}=1 \quad \text { (for } \forall i\right) \\
& \left.\mathrm{x}_{\mathrm{ijt}} \leq \mathrm{c}_{\mathrm{ij}} \quad \text { (for } \forall \mathrm{i}, \mathrm{j}, \mathrm{t}\right) \\
& \mathrm{x}_{\mathrm{ijt}} \leq z_{\mathrm{it}} \quad(\text { for } \forall \mathrm{i}, \mathrm{j}, \mathrm{t}) \\
& \sum_{\mathrm{i}} \sum_{\mathrm{j}} \mathrm{x}_{\mathrm{ijt}} \mathrm{a}_{\mathrm{i}} \leq \alpha \mathrm{ca}_{\mathrm{t}} \quad(\text { for } \forall \mathrm{t}) \\
& \mathrm{x}_{\mathrm{ijt}} \mathrm{l}_{\mathrm{i}} \leq \mathrm{l}_{\mathrm{t}} \quad \text { (for } \forall \mathrm{i}, \mathrm{j}, \mathrm{t} \text { ) } \\
& \mathrm{x}_{\mathrm{ijt}} \mathrm{w}_{\mathrm{i}} \leq \mathrm{w}_{\mathrm{t}} \quad(\text { for } \forall \mathrm{i}, \mathrm{j}, \mathrm{t}) \\
& \mathrm{x}_{\mathrm{ijt}} \in\{0,1\} \\
& \mathrm{y}_{\mathrm{jt}} \in\{0,1\}
\end{aligned}
$$

Figure 2: Integrated planning model

The objective function (1) is twofold: Minimisation of the number of setups at the pressbrake. There is a time associated with every production layout $\mathrm{j}$ used per sheet. This setup time is taken equal to a fixed value $f_{j t}$, independent of the sequence of the toolchanges. Afterwards, when applying a TSP, sequencedependent setup times are used. Minimisation of the makespan: the total production time per sheet should be minimised.

Constraints (2) make sure that a job can only be assigned to a certain production layout on a sheet, if that layout is selected for that particular sheet. (3) indicate that each job can be assigned only to one layout and can only be nested once. (4) limit the layouts that can be used for a certain job. (5) verify if a job can indeed be nested on a certain sheet, based 
on the material type and the sheet thickness. (6) guarantee that the total usable area $\left(\mathrm{ca}_{\mathrm{t}}\right)$ of a sheet is not exceeded when nesting the different jobs. A safety zone is taken into account ( $\alpha$ ). (7) and (8) check the length and width of a job compared to the length and width of a particular sheet.

Although the number of variables increases drastically as the number of jobs and/or production layouts increases, a standard mixed integer linear programming approach can solve the integrated planning model within reasonable computational time for small to medium sized instances up to 200 parts and 20 sheets. Further research will be needed to develop a dedicated heuristic to generate feasible production plans for larger instances. 


\subsection{Procedure}

First, the integrated model, as previously discussed, will be solved, determining the minimum number of production layouts and grouping the different parts on the sheets. This results per sheet in a number of orders, all with a certain toolset. In a second stage, a TSP is applied to sequence the jobs (per sheet) on the pressbrake. Both steps are integrated in a single application. The final results of the integrated model are thus (1) the different parts to be grouped on a sheet for laser cutting and (2) the tools to use at the pressbrake and the sequence for bending the parts.

After the first run of the model, nesting software is used to verify the model's ability to generate feasible groupings of parts. If the generated groupings cannot be nested, the sheet's characteristics are adapted. .

For the production planning model some important data requirements need to be fulfilled. First, the parts' characteristics, sheets' characteristics and the production layouts are needed. The part's characteristics and the sheet's dimensions, can be extracted from the CAD-file. The production layout is determined by dedicated software, but can alternatively be determined based on the pressbrake operator's experience. . All data is put in datasheets to be linked with the planning model.

Second, the laser cutting times and the bending times are needed. The laser cutting times can be estimated by a simple regression technique, while the bending times are determined by means of a time-motion study ( $P$. Vansteenwegen and J. Geysen 2002). The possible layout-job combinations are determined by an experienced planner and are summarised in a 0-1 matrix.

A case study has been worked out to verify if standard OR techniques can indeed be used to generate feasible integrated production plans for sheetmetal 
operations. The case study presented in this paper comprises 31 jobs, both profiles and complex parts, having different sheet thicknesses and geometrical shapes. Figure 3 shows some parts as used in the batch of 277 parts.

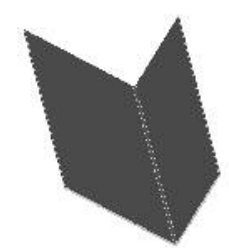

Bend lines

Name

Surface

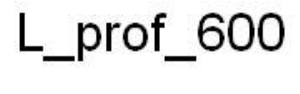

0.6

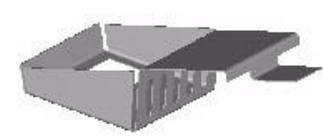

7

28030_b

0.0624

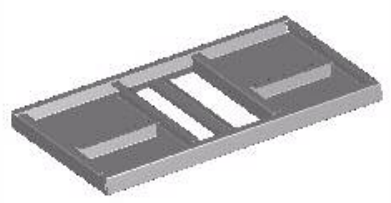

16

Autodemo

0.46

Figure 3: Sample of the data-set

The different situations to test are summarised in table 1.

\begin{tabular}{l|c|c|c} 
& Thickness & Materials & Parts \\
\hline 1mm_both & $1 \mathrm{~mm}$ & Steel, Stainless Steel & Complex, Profiles \\
1.5mm_both & $1.5 \mathrm{~mm}$ & Steel, Stainless Steel & Complex, Profiles \\
2mm_both & $2 \mathrm{~mm}$ & Steel, Stainless Steel & Complex, Profiles \\
$3 \mathrm{~mm}$ both & $3 \mathrm{~mm}$ & Stainless Steel & Complex, Profiles \\
6mm_both & $6 \mathrm{~mm}$ & Stainless Steel & Complex, Profiles \\
Small_thickness & $1 \mathrm{~mm}, 1.5 \mathrm{~mm}, 2 \mathrm{~mm}$ & Steel, Stainless Steel & Complex, Profiles \\
Small_profiles & $1 \mathrm{~mm}, 1.5 \mathrm{~mm}, 2 \mathrm{~mm}$ & Stainless Steel & Profiles \\
Small_complex & $1 \mathrm{~mm}, 1.5 \mathrm{~mm}, 2 \mathrm{~mm}$ & Steel, Stainless Steel & Complex \\
Large_profiles & $3 \mathrm{~mm}, 6 \mathrm{~mm}$ & Stainless Steel & Profiles \\
Large_complex & $3 \mathrm{~mm}, 6 \mathrm{~mm}$ & Stainless Steel & Complex
\end{tabular}

Table 1: Different situations to test

Different combinations of parts have been worked out to represent different realistic situations. Certain companies will focus on piecewise production of complex parts, while others will mainly produce larger series of profiles. For laser cutting, a $2 \mathrm{~kW}$ laser source is used and sheet dimensions are $3.5^{\star} 2.5$ metres. For the cutting process, 600 additional seconds with a deviation of $20 \%$ have been assigned to the operations prior to cutting. This time is used for 
preparing the laser machine for production, positioning the sheet and adapting the lenses and nozzles if necessary.

The results of the production planning model are for each situation compared to a reference case. This reference case represents the current way of planning that specific batch of orders For these reference cases, nesting is carried out with dedicated software as is the case in many companies. The different parts are grouped on sheets and sent to the pressbrake sheet per sheet. At the pressbrake, the best production layout is selected per part, based on the experience of the pressbrake operator. . For the reference case,: profiles are bent first, followed by the complex parts, grouped according to their surface.

\subsection{Simulation}

The integrated approach as proposed in this paper is only useful if both the cutting and bending process are balanced to some extent. The parts follow a unidirectional flow and only a small inventory is built in front of the pressbrake. If however, one of the processes becomes dominant, an integrated planning approach becomes useless. Attention should shift towards the bottleneck machine and bottleneck scheduling is more appropriate (Goldrath 1987, Neely 1992, Gardiner 1993). Simulation of the specific situation can be used to verify if the process is indeed balanced within specified limits. If this is the case, the integrated approach should be used. A simulation model is programmed to check whether the production situation is indeed balanced. To verify the balance of both production steps, the utilisation rates of both machines are compared to one another. If the ratio of the individual utilisation rates exceeds 2 or is below 0.5 , one of both machines is clearly dominant. In such cases, an integrated approach is useless. From table 2, displaying the ratios for the different situations, it can be seen that for large thicknesses (6mm, large_profiles and large_complex), an 
integrated approach becomes useless. This can be explained due to the fact that the time required for cutting increases drastically as the thickness increases. However, the bending time does not increase accordingly, hence explaining the high utilisation ratio. In those cases, the laser machine will be determinant for planning.

\begin{tabular}{l|c|c} 
& Ratio utilisation rates & Integrated Model applicable? \\
\hline 1mm_total & 1.24 & yes \\
1_5mm_total & 0.58 & yes \\
2mm_total & 1.37 & yes \\
3mm_total & 0.91 & yes \\
6mm_total & 11.78 & no \\
Small_thickness & 0.78 & yes \\
Small_profiles & 1.87 & yes \\
Small_complex & 0.56 & yes \\
Large_profiles & 11.12 & no \\
Large_complex & 3.09 & no
\end{tabular}

Table 2: Simulation results: ratio utilisation rates

In the simulation model, the parts arriving in the shop are grouped based on their sheet thickness, as is the case in real manufacturing companies. The parts will arrive based on a specific distribution or on-hand orders.

If the required minimum batch size for nesting is obtained, a sheet is filled and the parts are sent to the laser machine. Ten minutes are reserved for preparing the sheet and reading the NC file. Cutting times are estimated based on the parts' characteristics. After the parts are cut, they are sent to the bending machine. A transportation time of five minutes has been included for moving the parts from the laser machine to an inventory area in front of the pressbrake. At the pressbrake, the sheet will be unbatched and the parts will be bent individually. Here also, bending times are estimated based on the part's characteristics. 


\section{Results}

\subsection{Small-profiles situation}

To discuss the method used and the results obtained, one situation has been worked out completely. The "small profiles" batch comprises seven jobs and totals 23 parts of three different thicknesses. After applying the integrated approach as proposed in this paper, the production plan as shown in table 3 is obtained:

\begin{tabular}{|c|c|c|c|c|c|c|c|}
\hline 20 & & & ODDUCTION PLANNIN & MODULE: Final resL & & & \\
\hline$\$ 1$ & Sheet $1(1 \mathrm{~mm})$ & Sheet $2(1 \mathrm{~mm})$ & Sheet $3(1 \mathrm{~mm})$ & Sheet $4(1 \mathrm{~mm})$ & Sheet $5(1.5 \mathrm{~mm})$ & Sheet $6(1 \mathrm{~mm})$ & Sheet $7(2 \mathrm{~mm})$ \\
\hline$\$ 2$ & L_prof_1_3000(Set1) & L_prof_1_3000(Set1) & L__prof_1_3000(Set1) & L_prof_1_3000(Set1) & L_prof_1.5_2000(set4) & u_prof_1(Set5) & u_prof_2_2500(Set69) \\
\hline 40 & L__prof_1_3000(Set1) & L__prof_1_3000(Set1) & L__prof_1_3000(Set1) & L_prof_1_3000(Set1) & L_prof_1.5_2000(set4) & L_prof_1_1320(Set2) & u_prof_2_2500(Set69) \\
\hline 23 & & & & & & L_prof_1_1320(Set2) & u_prof_2_2500(Set69) \\
\hline$\$ 4$ & & & & & & L__prof_1_600(Set2) & u_prof_2_2500(Set69) \\
\hline$\$ 5$ & & & & & & L__prof_1_600(Set2) & u_prof_2_3000(Set69) \\
\hline 86 & & & & & & L__prof_1_600(Set2) & u_prof_2_3000(Set69) \\
\hline 87 & & & & & & L_prof_1_600(Set2) & \\
\hline f'UTTING TIME (s) & 160 & 160 & 160 & 160 & 184 & 235 & 518 \\
\hline ENDING TIME (s) & 56 & 56 & 56 & 56 & 80 & 270 & 268 \\
\hline TUP PRESSBRAKE (s) & 0 & 0 & 0 & 124.4 & 242.7 & 278.8 & 0 \\
\hline
\end{tabular}

Table 3: Final result planning module

After including preparation time for each sheet, and a possible waiting time in front of the pressbrake, a makespan of 7,065 seconds is determined. The results from the planning model need to be compared to the reference case. For the reference case, all parts included in this situation are grouped in a pool to be nested with dedicated nesting software. Next, the sheets as generated by the software, are sent to the pressbrake one by one. The production layouts are determined based on an operator's experience. For sequencing the parts, the rules as explained in paragraph 3 are used. 


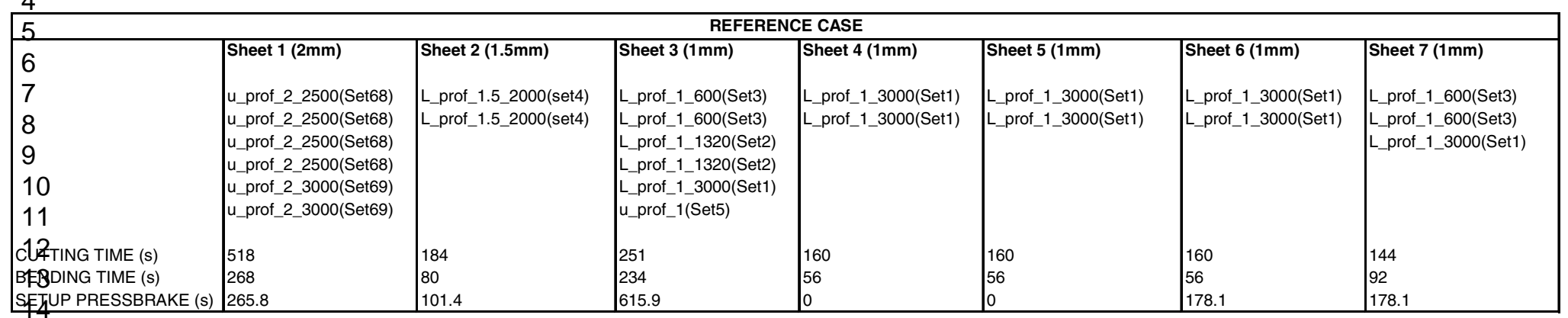

Table 4: Reference case for the small profiles situation

This separate planning of the distinct processes results in a makespan of 7,481 seconds. Thus for this particular small batch, a makespan reduction of $5.5 \%$ is obtained. If the same batch would be produced continuously, one would be able to save 13.5 working days per year, given that there are 244 working days of 8 hours per year.

The number of toolchanges drops from 10 to 4 and the setup time is reduced by $56 \%$ compared to the reference case. The same approach is used for all other situations as mentioned in paragraph 3. Even the situations with an apparent bottleneck were planned with the integrated model to verify if the applicability is indeed very low.

Besides the reduced makespan, the material utilisation needs to be analysed. If the integrated approach results in a need for additional sheets, this extra material cost should be compared to the benefits from a reduced makespan. For the small-profiles situation, no additional sheets are required. The only difference between the reference case and the integrated model's result is the layout of the nested parts and hence the geometry of the remnant sheets, i.e. sheets that are partially used and stored for later use. The surface of the remnant sheets remains the same since the total surface to nest is identical for both cases, but the geometry can be different due to grouping of different parts (note that rectangular remnant sheets are preferred). 


\subsection{Generation time}

The total computational time remains within acceptable limits. By applying branch and bound techniques, the optimal solution is found within a few minutes. If the problem size increases, the exact algorithm is unable to find an optimal solution within an acceptable time. Future research will therefore focus on the development of a dedicated heuristic to solve the integrated planning model.

When looking for an appropriate heuristic, resemblances with existing OR-models could be useful. Similarities with the capacitated plant location problem (CPLP) can be detected, but adaptations are required. The CPLP decides were to locate capacitated facilities, such that the fixed opening cost of a facility and the total cost of supplying customers is minimised (Christofides 1983). In the integrated planning problem we assign jobs to sheets (customers to plants), but every job also needs to be assigned to a certain toolset. More similarities can be found with the vehicle routing problem (VRP). A number of trucks with a fixed capacity are available to drive to different customers. Each customer has a certain demand and a certain distance from a central depot. The goal is to find the minimum number of tours to serve all customers, taking into account the limited capacity of a truck. After each tour, the truck returns to the central depot to load/unload. In our specific case, the trucks represent sheets with a limited capacity and the customers are the jobs to be nested on a sheet. The demand corresponds to the surface of the part. The distances between the different customers are the sequence-dependent setup times between the toolsets assigned to a job. Additional research is needed to develop a local search method to generate integrated production plans for larger problem instances.

Table 5 summarizes the final results for all situations tested: 


\begin{tabular}{|c|c|c|c|c|c|c|c|}
\hline & Model applicable? & Sheets reference & Sheets model & Makespan reduction (\%) & Setup time reduction(\%) & Reduction (days/yr) & Standard Deviation (days) \\
\hline $1 \mathrm{~mm} \_$total & yes & 6 & 6 & 10.45 & 57.00 & 25.50 & 1.90 \\
\hline 1_5mm_total & yes & 3 & 3 & 2.02 & 14.00 & 4.92 & 0.28 \\
\hline 2mm_total & yes & 2 & 2 & 2.89 & 26.00 & 7.07 & 0.79 \\
\hline 3mm_total & yes & 3 & 3 & 1.01 & 9.00 & 2.46 & 0.10 \\
\hline $6 \mathrm{~mm} \_$total & no & 23 & 23 & 0.14 & 96.00 & 0.35 & 0.00 \\
\hline Small_thickness & yes & 12 & 12 & 4.07 & 42.00 & 9.94 & 0.45 \\
\hline Small_profiles & yes & 7 & 7 & 5.56 & 56.00 & 13.56 & 0.88 \\
\hline Small_complex & yes & 7 & 7 & 2.78 & 19.00 & 6.80 & 0.35 \\
\hline Large_profiles & no & 9 & 9 & 0.23 & 86.00 & 0.55 & 0.07 \\
\hline Large_complex & no & 14 & 14 & 0.36 & 9.00 & 0.90 & 0.02 \\
\hline AVERAGE & & & & 4.10 & 31.80 & 10.00 & 0.67 \\
\hline
\end{tabular}

Table 5: Results for the different test situations

Table 5 shows that on average, a makespan reduction of $4.1 \%$ can be obtained. Translating this to yearly savings expressed in days, results in an average reduction of 10 working days per year. Of course, depending on the specific type of production (profiles or mainly complex parts), the reduction can be larger or smaller. The highest makespan reduction occurs for small thicknesses, comprising mainly profiles. The standard deviation is calculated for all situations by taking the square root of the squared deviations for all distinct steps: preparing the sheets for cutting, cutting the parts, preparing the parts for bending, bending the parts with setups in between production layouts.

The time required for toolchanges decreases on average with $31.8 \%$. This value is obtained mainly by grouping the different sheets in such a way that no additional setups are needed between subsequent sheets.

If large thicknesses are included, the laser machine becomes the bottleneck. In that case, an integrated approach is useless as can be seen by the very low percentages of makespan reduction. Simulation confirms the results from the planning module: if a machine is clearly dominant, bottleneck scheduling is preferred over an integrated approach. Indeed, if large thicknesses are to be processed, the cutting time increases drastically, but the bending time does not increase accordingly. The laser machine becomes dominant and the reduction in bending time due to an integrated planning approach has very little impact. 
For all situations that have been run, the number of sheets does not increase when using the integrated approach compared to dedicated nesting software. When using the nesting software, sheet utilisation rates of about maximum $75 \%$ are obtained. Applying the integrated planning model yields utilisation rates of about the same magnitude, without requiring additional sheets.

\section{Conclusions}

To overcome the problem of sub-optimisation for sheetmetal production planning, an integrated production planning model aiming at makespan reduction is proposed.. In literature, no integrated planning approach has been proposed since sequentially optimising the distinct processes is the current way of planning sheetmetal operations.

By combining the parts in an intelligent way for laser cutting, however, the number of setups at the pressbrake can be reduced. The integrated approach first minimises the number of toolsets while grouping them to different sheets. Next, by applying a TSP, the sheets are ordered for cutting and the jobs are sequenced for bending. This sequence for bending has no influence on the nesting of the parts on the different sheets. Prior to running the model, simulation can be used to check if the production situation is somewhat balanced. If this is not the case, bottleneck scheduling should be applied instead of an integrated approach. Typically, if larger thicknesses are present, the laser machine becomes the bottleneck since the cutting time increases drastically with the thickness, while the bending times does not increase accordingly. In cases where an apparent bottleneck can be found, bottleneck scheduling techniques are more appropriate.

A number of different situations were run to verify the model's ability to generate good production plans. On average a makespan reduction of $4.11 \%$ can be obtained, resulting in a yearly reduction of 10 working days (244 working days 
per year, 8 hours per day). Statistical analysis of the results revealed that the average standard deviation for the makespan is 0.67 days.

The benefits from the makespan reduction need to be balanced against the possible increased material utilisation. If additional sheets are required, the material cost might outweigh the makespan reduction. For the different situations tested, only a small average reduction of the utilisation rate is found. No additional sheets are needed and the material cost will hence not increase substantially.

Further research is required to allow modelling different situations. Multiple machines and larger problem sizes should be handled within a reasonable computational effort. A dedicated heuristic needs to be developed to limit the calculation time.

Acknowledgments

The authors acknowledge the financial support from IWT Vlaanderen (IWT 040340) and helpful comments raised by all anonymous referees. 


\section{References}

Adamowicz, M. and Albano, A., Nesting two-dimensional shapes in rectangular modules. Computer aided design 8, 1976, pp. 27-33.

Agrawal, P.K., Minimizing trim loss in cutting rectangular blanks of a single size from a rectangular sheet using orthogonal guillotine cuts. European journal of operational research 64,1993, pp. 410-422.

Buckley, J., Chan, A., Graefe, U., Neelamkavil, J., Serrer, M. and Thompson, V., An integrated production planning and scheduling system for manufacturing plants. Robotics and computer integrated manufacturing 4 , 1998, pp. 517-523.

Cheng, C.H., Feiring, B.R. and Cheng, T.C., The cutting stock problem: a survey. International journal of production economics 36, 1994, pp. 291-305.

Chow, W.W., Nesting of a single shape on a strip. International journal of production research 17, 1979, pp.305-322.

Christofides, N. and Beasley, JE., Extensions to a Lagrangean relaxation approach for the capacitated warehouse location problem. European journal for operational research 12, 1983, pp. 19-28.

Collin, P., Van Oudheusden, D., Cattrysse, D. and Duflou, J.R., A travelling purchaser formulation for sheetmetal bending production planning.

Proceedings of 10th international conference on sheetmetal, 2003, pp. 279286.

Dagli, C.H., Neural networks in manufacturing: possible impacts on cutting stock problems. Proceedings of the Rensselaer $2^{\text {nd }}$ international conference on CIM, 1990, pp. 531-537. 
Duflou, J.R., Váncza, J. and Aerens, R., Computer aided process planning for sheetmetal bending: A state of the art. Computers in industry 56, 2005, pp. 747-771.

Farley, A.A., Mathematical programming models for cutting stock problems in the clothing industry. Journal of the operational research society $39,1988, \mathrm{pp}$. 41-53.

Fries-Knoblach,J., Sheetmetal working in bronze age and iron age in Southern Central Europe. Proceedings of 7th international conference on sheetmetal, 1999, pp. 23-36.

Gardiner, S. C, Blackstone J.H. and Lorraine, R., Drum-Buffer-Rope and buffer management: Impact on production management study and practices. International journal of operations \& production management 13, 1993, pp. 68-78.

Gilmore, P.C. and Gomory, R.E., A linear programming approach to the cutting stock problem. Operations Research 9, 1965, pp. 849-859.

Goldratt, E. and Cox, J., The Goal: A process of ongoing improvement, 1987 (North River Press: New York).

Grinde, R.B. and Cavalier, T.M., A new algorithm for the minimal area convex enclosure problem. European journal of operational research 84, 1995, pp. 522-538.

Lin, Z.C. and Chang, D.Y., Application of a neural network machine learning model in the selection system of sheetmetal bending tooling. Artificial intelligence in engineering 10, 1996, pp. 21-37.

Murty, K.G., Linear programming, 1983 (Wiley: New York) 
Nee, A.Y.C., A heuristic algorithm for optimum layout of metal stamping blanks. Annals of the CIRP 33, 1984, pp. 317-320.

Neely, A.D. and Byrne, M.D., A simulation study of bottleneck scheduling. International journal of production economics 26, 1992, pp.187-192.

Nguyen, T.H.M., Duflou, J.R. and Kruth, J.P., A framework for automatic tool selection in integrated CAPP for sheetmetal bending. Proceedings of 11 th international conference on sheetmetal, 2005, pp. 287-295.

Nye T.J., Optimal nesting of irregular convex blanks in strips via an exact algorithm. International journal of machine tools \& manufacture $41,2001, \mathrm{pp}$. 991-1002.

Oliveira, J.F.C. and Ferreira, J.A.S., Algorithms for nesting problems. Applied simulated annealing, lecture notes in economics and mathematical systems 396, 1993, pp. 256-273.

Ong, S.K., De Vin, L.J., Nee, A.Y.C. and Kals, H.J.J., Fuzzy set theory applied to bend sequencing for sheetmetal bending. Journal of materials processing technology 69, 1997, pp. 29-36.

Poshyanonda, P.,Dagli, C.H., A hybrid approach to composite stock cutting: neural networks and genetic algorithms. Robotics and Manufacturing: recent trends in research, education and applications 4, 1992, pp. 775-780.

Prasad, Y.K.D.V., Somasundaram, S. and Rao, K.P., A sliding algorithm for optimal nesting of arbitrarily shaped sheetmetal blanks. International journal of production research 33, 1995, pp.1505-1520.

Riane, F., Artiba, A. and lassinovski, S., An integrated production planning and scheduling system for hybrid flowshop organizations. International journal of production economics 74,2004 , pp. 33-48. 
Schultz, T.A., Application of linear programming in a gauge splitting operation. Operations research 43, 1995, pp. 752-757.

Serruys, W., Sheetmetalworking: state of the art, pp. 9, 2002 (LVD Company: Belgium).

Suliman, S.M.A., A sequential heuristic procedure for the two dimensional cutting stock problem. International journal of production economics 99, 2006, pp. 177-185.

Vansteenwegen, P. and Geysen, J., Bewegingsanalyse en tijdsraming voor buigprocessen. Master's Thesis Mechanical Engineering, Katholieke Universiteit Leuven, 2002. 